\title{
TRADIÇÃO E SOCIALIZAÇÃO NOS TERREIROS DE CANDOMBLÉ DE UBERABA-MG: ANÁLISE BIOECOLÓGICA DOS PERCURSOS RELIGIOSOS
}

\author{
LA TRADICIÓN $\Upsilon$ LA SOCIALIZACIÓN EN LOS TERREIROS \\ DE CANDOMBLÉ DE UBERABA-MG: ANÁLISIS BIOECOLÓGICA \\ A PARTIR DE LAS TRAYECTORIAS RELIGIOSAS \\ THE TRADITION AND SOCIALIZATION IN \\ THE CANDOMBLÉ CENTERS OF UBERABA-MG: \\ BIOECOLOGICAL ANALYSIS OF RELIGIOUS TRAJECTORIES
}

\author{
Fabio Scorsolini-Comin ${ }^{1}$, Ariadne Christie Silva Ribeiro ${ }^{2}$ \\ e Ronan da Silva Parreira Gaia ${ }^{1}$ \\ ${ }^{1}$ Universidade de São Paulo, Ribeirão Preto/SP, Brasil \\ ${ }^{2}$ Universidade Federal do Triângulo Mineiro, Uberaba/MG, Brasil
}

\begin{abstract}
RESUMO: Este estudo teve por objetivo compreender, a partir de uma análise bioecológica, como se dão as relações entre tradição e sociabilidade em terreiros de Candomblé da cidade de Uberaba-MG, Brasil, a partir das narrativas desenvolvimentais de seus adeptos. Foram entrevistados 14 adeptos de dois terreiros de nações diferentes (Ketu e Efon), com pelo menos sete anos de iniciação. Os resultados indicaram forte tradição e transmissão geracional e oral de conhecimentos. As relações interpessoais nos terreiros são fraternas e resgatam elementos da hierarquia familiar, com forte percepção do apoio social dessa rede. Os entrevistados, pelo tempo de iniciação, assumem a responsabilidade de transmitir os conhecimentos religiosos, preservando a tradição. Este estudo evidenciou como as noções de tradição e sociabilidade atravessam os processos desenvolvimentais dos adeptos do Candomblé, permitindo a construção de normas, relações e itinerários que encontram nas comunidades de referência um espaço de acolhimento e pertencimento.
\end{abstract}

PALAVRAS-CHAVE: Cultos afro-brasileiros; Crenças religiosas; Candomblé; Desenvolvimento humano.

RESUMEN: Este estudio tuvo por objetivo comprender, a partir de un análisis bioecológico, cómo se dan las relaciones entre tradición y sociabilidad en terreiros de Candomblé de la ciudad de Uberaba-MG, Brasil, a partir de las narrativas desarrollativas de sus adeptos. Se entrevistaron a 14 adeptos de dos terreiros de naciones diferentes (Ketu y Efon), con al menos siete años de iniciación. Los resultados indicaron fuerte tradición y transmisión generacional y oral de conocimientos. Las relaciones interpersonales en los terreros son fraternas y rescatan elementos de la jerarquía familiar, con fuerte percepción del apoyo social de esa red. Los entrevistados, por el tiempo de iniciación, asumen la responsabilidad de transmitir los conocimientos religiosos, preservando la tradición. Este estudio evidenció cómo las nociones de tradición y sociabilidad atraviesan los procesos desarrollativos de los adeptos del Candomblé, permitiendo la construcción de normas, relaciones e itinerarios que encuentran en las comunidades de referencia un espacio de acogida y pertenencia.

PALABRAS CLAVES: Cultos afrobrasileños; Creencias religiosas; Candomblé; Desarrollo humano.

ABSTRACT: This study aimed to understand, from a bioecological analysis, how the relationships between tradition and sociability in Candomblé centers of the city of Uberaba-MG, Brazil, are based on the developmental narratives of their followers. We interviewed 14 followers from two centers of different nations (Ketu and Efon), with at least seven years of initiation. The results indicated strong tradition and generational and oral transmission of knowledge. Interpersonal relationships in the Candomblé meeting places are fraternal and rescue elements of the family hierarchy, with a strong perception of the social support of this network. The interviewees, by the time of initiation, assume the responsibility of transmitting the religious knowledge in order to preserve the tradition. This study showed how the notions of tradition and sociability cross the developmental processes of Candomble followers, allowing the construction of norms, relationships and itineraries that find in the communities of reference a space of welcome and belonging. KEYWORDS: Afro-Brazilian cults; Religious beliefs; Candomblé; Human development. 


\section{Introdução}

O universo religioso de matriz africana oferece uma extensa gama de possibilidades de investigação, desde aspectos específicos relacionados às divindades e/ou às incorporações, passando pelas relações sociais, culturais e comunitárias observadas nesse contexto. Investigar uma religião de matriz africana é também estudar uma das raízes culturais brasileiras, já que suas origens remontam aos principais grupos formadores da nossa cultura e da sociedade (Pierucci, 2004). Todavia, ao se perscrutar a tradição em pesquisas no campo da Psicologia, nota-se um predomínio nos temas religiosos de valorizarem patologias e o funcionamento psíquico considerado anormal (Moreira-Almeida, 2013), em detrimento de questões cruciais, a exemplo do modo como essas religiões se organizam e contribuem para compreender a sociabilidade nas mais diversas comunidades de terreiro (Brant Carvalho \& Bairrão, 2017; Castillo, 2017; Scorsolini-Comin, 2017).

Os estudos sobre as religiões de matriz africana revelam o poder da tradição, da ancestralidade e da transmissão oral de saberes, justificadas não somente em razão da escassez de textos e manuscritos sagrados escritos pelos precursores destas religiões ou pelos fatores sócio-históricos que remontam à história da escravidão e à chegada do negro africano no país, mas também pela oralidade ser uma prática comum na África (Goldman, 2012; Rabelo, 2014). A tradição oral tornou-se um meio importante para a persistência dessas culturas na condição de escravidão (Santos \& Alves, 2017), tal como segredos, práticas e hierarquias (Araújo, 2018). Essas culturas se perpetuam com o passar do tempo, promovendo tanto a reconceituação do que é tradicional, ainda que com resistência de alguns adeptos que prezam pelo que concebem por "tradição" - esta será compreendida neste aspecto como reprodução das práticas dos responsáveis por instaurar os procedimentos do culto - quanto certa abertura para que algumas transformações possam ser assimiladas nas mais diferentes comunidades de terreiros (Bastide, 2009; Prandi, 1990; Verger, 2002).

O diálogo entre tradição e inovação é possível, muitas vezes, devido à junção com elementos de outras religiões, a exemplo do que ocorre com a umbanda, conhecida por ser uma religião brasileira que mescla aspectos trazidos pelo candomblé, pelo espiritismo e pelo catolicismo, cultuando orixás e entidades (Brant Carvalho \& Bairrão, 2017; Macedo \& Bairrão, 2011; Scorsolini-Comin, 2017). Assim, observa-se que as religiões de matriz africana acabam por ser constituídas nessa interface que recupera o antigo, o tradicional, o ancestral, ao mesmo tempo em que permitem, em certa medida, a assimilação do novo, a elaboração criativa das reinvenções e o acréscimo de determinados ajustes em termos de práticas, preceitos e rituais (Goldman, 2012).

Ao analisar a tradição é necessário, acima de tudo, destacar a importância desta para as religiões de matriz africana, tendo em vista o papel dos mais velhos, responsáveis por transmiti-las (Santos \& Alves, 2017) e a hierarquização etária da organização dos terreiros. É preciso compreender ainda que tradição diz respeito, segundo esses autores, a "toda forma de se comportar e proceder de um grupo social, que se fixa em seus membros e permanece na dimensão espaço-tempo" (p. 56).

Ainda é válido ressaltar, para pontuar uma perspectiva clássica da ideia de tradição, o trabalho de Hobsbawm (1984), que assinala o papel da mesma em garantir a invariabilidade, permitindo então formalizar normas e fixar práticas, tornando-as tradicionais. O conceito de ancestralidade é amplamente discutido nos terreiros. Doravante, podemos associar que isto se deva pelo fato da escassez de registros históricos sobre a prática do 
culto, derivados do período escravagista, de marginalização e criminalização do Candomblé (Cerqueira, 2007). O conhecimento ancestral repassado pela tradição, que garante a permanência dessa sabedoria entre as gerações, permite a sociabilidade no terreiro. Os adeptos são socializados através da tradição oral, que fixa as práticas sociais que constituem o terreiro e atravessa os modos como seus adeptos são iniciados.

No candomblé, ao ser iniciado, processo que simboliza uma saída da vida material e o nascimento para vida espiritual, o neófito, após passar pelos preceitos específicos da nação a qual seu terreiro pertence é chamado de Iyawo, quando iniciado na Nação Ketu ou Efon, Vodunci, quando iniciado na nação Jeje, e Muzenza quando iniciado na Nação Bantu/ Angola. Porém, quando cumpre a obrigação de sete anos, torna-se um Egbomi (meu irmão mais velho), na nomenclatura do candomblé Ketu e Efon. No Candomblé Jeje, torna-se Etemi (meu mais velho), no Candomblé Bantu/Angola, Maganza. Além do processo de iniciação, esses recém iniciados devem passar por rituais chamados de obrigação quando completam um, três, sete, 14 e 21 anos de iniciados. A obrigação de sete anos é considerada a mais importante, pois marca uma espécie de "maioridade religiosa" do iniciado. Nessa obrigação será definido se ele/a abrirá ou não um terreiro, recebendo postos, cargos ou títulos e independências de zelador (como pai ou mãe de santo) (Verger, 2002). Todas essas definições são apontadas e confirmadas através de consultas ao Érindílógún, o jogo de 16 búzios, de caráter adivinhatório. Convém expor que não basta desejar tornar-se um zelador de uma casa de axé, a pessoa traz a missão de se tornar um sacerdote já no seu nascimento, e isso está cravado irreversivelmente em seu destino. Por essa razão, eles são chamados de Omo Bibi (Bem Nascidos).

Os processos de iniciação e os modos como cada comunidade narram o desenvolvimento dos seus adeptos no Candomblé já foram alvo de estudos clássicos no campo das ciências sociais (Goldman, 2005, 2012; Rabelo, 2014), elegendo núcleos de destaque no país como os terreiros de Salvador (BA) e do Rio de Janeiro (RJ). No entanto, faz-se necessário compreender as trajetórias em comunidades que não gozam da mesma visibilidade, a exemplo das casas localizadas na cidade de Uberaba-MG. Esta cidade, localizada na região do Triângulo Mineiro, é considerada um núcleo religioso importante na cultura brasileira, reconhecida pela difusão do espiritismo kardecista, haja vista que lá residiu, por muitos anos, o conhecido médium Chico Xavier (Lewgoy, 2001; Scorsolini-Comin, 2017). Em um país tradicionalmente de maioria católica, esta região diferencia-se pela abertura a linhagens distintas, mesmo que permaneçam numa matriz ocidental. Haja vista o preconceito contra as religiões de matriz africana, tal como tudo o que vem do negro no Brasil, a predisposição a diferentes crenças pode ter contribuído para a disseminação também de terreiros nessa região, até mesmo pela busca de cura espiritual, comum à região e também oferecida por alguns Babalorixás e Iyalorixás por meio de consultas, guiadas pela medicina tradicional africana, sendo que Uberaba também se destaca pela existência de históricos serviços de saúde mental relacionados à religiosidade/espiritualidade (Jabert \& Facchinetti, 2011). Tais questões permitem considerar a cidade como um locus privilegiado para a investigação sobre religião em nosso país.

Trilhando o caminho de diversas investigações clássicas e contemporâneas que buscam descrever e compreender os movimentos de constituição do Candomblé (Castillo, 2017; Prandi, 1990; Santos \& Santos, 2013; Verger, 2002), o presente estudo teve por objetivo central entender como se dão as relações entre tradição e sociabilidade em alguns terreiros de Candomblé da cidade de Uberaba-MG, a partir das narrativas desenvolvimentais 
de seus adeptos. As trajetórias religiosas, que incluem os percursos de socialização religiosa, como abordado por Rabelo (2014), devem incluir aspectos que não se centram apenas nos adeptos, sugerindo uma abordagem individualista, mas também os contextos interativos, o que se mostra particularmente possível por meio de uma investigação bioecológica como a aqui empreendida (Camargo, Scorsolini-Comin, \& Santos, 2018) e realizada em estudos anteriores com adeptos da umbanda, por exemplo (ScorsoliniComin \& Campos, 2017). O mapeamento realizado neste estudo é importante para que se compreenda como essas religiões ancoraram-se em um município com forte tradição religiosa, compreendendo a sociabilidade como forma dessas comunidades dialogarem com os desafios e as vicissitudes contemporâneas que atravessam todo e qualquer fenômeno religioso e sua ressonância nos percursos desenvolvimentais de seus adeptos.

Ademais, em um cenário nacional marcado pelo aumento da intolerância religiosa e pelos ataques recorrentes a espaços sagrados, sobretudo os relacionados às tradições afro-brasileiras (Simões \& Salaroli, 2017), é importante ampliar a visibilidade dessas comunidades, não apenas em termos institucionais, mas de suas tradições e de seus adeptos. Assim, espera-se contribuir não apenas para que tais comunidades sejam mais conhecidas, mas também para que possam se firmar e serem reconhecidas e legitimadas como espaços de resistência e pertencimento às pessoas que delas participam e que encontram nesses ambientes um forte contexto promotor de amadurecimento emocional, cuidado e desenvolvimento social. Tratar das tradições e das socializações operadas nessas comunidades é uma forma de ampliar o diálogo em torno de uma cultura de respeito à diversidade e às expressões religiosas, permitindo que essas comunidades possam se desenvolver a despeito de movimentos que tentam silenciá-las.

\section{Método}

\section{Tipo de estudo e considerações éticas}

Estudo qualitativo, descritivo, de abordagem bioecológica, aprovado pelo Comitê de Ética em Pesquisa da Escola de Enfermagem de Ribeirão Preto da Universidade de São Paulo (CAAE 88314618.9.0000.5393).

\section{Participantes}

Para participarem do estudo, os adeptos necessariamente tinham que ter passado pela obrigação dos sete anos, ser maior de idade e frequentar regularmente algum terreiro da cidade de Uberaba. A escolha da obrigação de sete anos deveu-se ao fato de esses adeptos possivelmente demonstrarem maior engajamento na religião, conforme orientado pelos Babalorixás e Yalorixás dos terreiros visitados, bem como conhecimentos mais apurados acerca de suas tradições (Goldman, 2012), à medida que chegaram até a maioridade. A amostra foi composta por 14 participantes vinculados a dois terreiros da cidade de Uberaba-MG, de duas nações distintas: Ketu e Lokiti Efon (que neste estudo será referida simplesmente como Efon). Cumprindo as especificidades metodológicas deste estudo, os participantes estavam inseridos na religião há mais de sete anos e desenvolviam atividades mediúnicas regulares, com frequência mínima de uma vez ao mês. A média de idade 
dos participantes foi de 32 anos, variando de 21 a 63 anos. A média de idade de santo foi de 19,5 anos, com a variação entre sete e 52 anos. Os participantes exerciam diferentes funções dentro de suas casas de axé. O nível de escolaridade variou desde ensino básico completo até a pós-graduação. O número de participantes foi definido a partir da disponibilidade de acesso aos mesmos e pelos critérios de saturação.

\section{Instrumento}

Para a coleta de dados, foi utilizado um roteiro de entrevista. O conjunto de perguntas consistiu basicamente em um levantamento dos seguintes dados: idade, idade de santo, tempo de frequência na religião, escolaridade, emprego/ocupação, estrutura familiar e redes de apoio, funcionalidades e celebrações do lugar, percepções acerca da mediunidade e da religião, o contato com a comunidade, vantagens e desvantagens da escolha espiritual e experiências relacionadas à espiritualidade, ao terreiro e à feitura do santo.

\section{Procedimento}

Coleta de dados. Preliminarmente, por meio de indicações de contatos sociais dos pesquisadores, foi feita uma listagem de endereços e dias de funcionamento dos 11 terreiros identificados na cidade, os mais conhecidos e/ou maiores. Desses, nove foram visitados para se conhecer os diferentes tipos de culto e verificar os que seriam mais viáveis para o estudo. Consequentemente, cinco zeladores de santo foram contatados para explicar o objetivo da pesquisa; dois se mostraram abertos e disponíveis à proposta. Todas as observações ao longo dessas visitas e da coleta de dados foram registradas em diário de campo, subsidiando também a construção da análise. Em cada terreiro pesquisado, prioritariamente, foi realizada uma entrevista, a priori, com os dirigentes do local. Isso permitiu obter o consentimento para as demais entrevistas e propiciou a indicação de alguns participantes, sendo eles os mais antigos (por idade de feitura). Em outras ocasiões, foram selecionados os participantes diretamente por meio de sua frequência aos terreiros e conhecimento da idade de feitura de voluntários em potencial. Após os esclarecimentos e a assinatura do Termo de Consentimento Livre e Esclarecido, as entrevistas foram aplicadas individualmente e audiogravadas. Ocorreram, de preferência, em dias que não coincidiam com as atividades religiosas, para não restringir o tempo de conversa. As entrevistas audiogravadas, bem como as histórias de vida, foram posteriormente transcritas na íntegra e compuseram o corpus analítico.

Análise dos dados. A interpretação dos dados foi pautada na bibliografia científica produzida sobre o candomblé brasileiro em diálogo com a teoria bioecológica do desenvolvimento de Bronfenbrenner (2011), que propõe a análise do desenvolvimento a partir da integração de quatro grandes níveis: (a) Pessoal, (b) Processual, (c) Contextual e (d) Temporal. O Contexto - como a família, o trabalho, a instituição religiosa - subdivide-se em quatro sistemas: micro, meso, exo e macrossistema.

Em um primeiro momento, a partir das narrativas, foram identificados os elementos ligados a esses níveis descritos por Bronfenbrenner (2011), de um modo descritivo. $\mathrm{O}$ aspecto "Pessoa", por exemplo, ressalta a importância de se considerar as características do indivíduo em desenvolvimento, como suas convicções, nível de atividade, temperamento, 
além de suas metas e motivações (Martins \& Szymanski, 2004). No candomblé, essas características envolvem, por exemplo, elementos como os orixás de cada pessoa, suas tipologias e comportamentos socialmente atribuídos aos seus adeptos iniciados e que também se relacionam aos cargos ocupados/assumidos nesses espaços. Características pessoais, como sexo/gênero ou cor da pele, que podem influenciar na maneira pela qual outros lidam com a pessoa em desenvolvimento, como valores e expectativas que se têm na relação social, também devem ser consideradas. Marcadores pessoais como esses podem nutrir ou romper a operação de processos de crescimento psicológico. Por ser uma abordagem de modelo integrado, esse aspecto "Pessoa" encontra-se profundamente ligado ao "Processo", já que o último tem a ver com as ligações entre os diferentes níveis e se acha constituído pelos papéis e atividades diárias da pessoa em desenvolvimento. A iniciação no candomblé, por exemplo, é um marcador do processo que se integra aos demais elementos do modelo bioecológico.

Após a identificação desses elementos, operou-se uma análise sistêmica, ou seja, integrando essas dimensões. Em Bronfenbrenner (2011), a identificação desses elementos cumpre uma tarefa importante, mas que não é equivalente a uma análise bioecológica. Essa análise sistêmica foi conduzida a partir de uma leitura integrada desses elementos, buscando em que medidas esses níveis se interpenetram e contribuem para uma compreensão orgânica e em movimento da pessoa em desenvolvimento. Além desses elementos, como o objetivo recobriu a investigação acerca das trajetórias desenvolvimentais, empregou-se a noção de transição ecológica, que evidencia a ocorrência dos processos de desenvolvimento (Bronfenbrenner, 2011; Poletto \& Koller, 2008). Segundo esse conceito empregado por Bronfenbrenner, toda transição ecológica envolve uma mudança de contexto e/ou de papel. Assim, quando a pessoa passa a desempenhar um novo papel ou muda de ambiente, está experienciando um processo de transição. Essa transição é uma evidência de que, de fato, o desenvolvimento está ocorrendo. No contexto do candomblé, a mudança de papel decorrente da iniciação (feitura do santo) ou da assunção de um novo cargo, por exemplo, pode evidenciar uma transição ecológica e, para além disso, corporificar o poder da tradição. O modelo bioecológico foi escolhido por permitir uma análise sistêmica dos processos desenvolvimentais dos adeptos, em atenção à complexidade do tema e à sua utilização em outros estudos sobre o candomblé e também sobre a umbanda (Camargo et al., 2018; Scorsolini-Comin \& Campos, 2017).

\section{Resultados e Discussão}

\section{Caracterização dos participantes e seus contextos desenvolvimentais}

A caracterização dos participantes a partir dos elementos da religiosidade do candomblé será apresentada como um marcador do nível "Pessoa", que trata das características pessoais dos adeptos, como anunciado no Método, mas também como um aspecto relacionado tanto ao Contex to macro (a religião do candomblé brasileiro) quanto ao mais imediato (do qual faz parte a pessoa em desenvolvimento, ou o microssistema), dentro do modelo bioecológico. Os participantes serão caracterizados, portanto, a partir dos aspectos da religião e das tradições envolvidas.

Segundo a bibliografia produzida acerca do candomblé, tanto na nação Ketu, como na nação Efon, o dialeto utilizado é o Korubá. O Orixá patrono da Nação Ketu desse estudo 
é Oxóssi, concebido pelos nagôs como a divindade responsável pela caça, sua saudação é Oke Arô (grande caçador) e é concebido como o Orixá que garante o alimento à sua aldeia. Já o terreiro de Nação Efon tem como patronesse a Orixá Oxum, o Orixá maternal, responsável pela água doce, dona do ouro e da beleza. Dentre as variadas formas de cultuar o sagrado dentro das religiões de matriz africana, essas duas nações serão priorizadas neste estudo: Ketu e Efon, à medida que estas deram espaço para realização da pesquisa em seus terreiros. Sobre a nação Ketu pode-se afirmar que é o nome de uma cidade que foi palco de guerras no final do século XVIII por se localizar entre estados rivais, Oyó e Daomé, respectivamente referentes a Ketu e Jeje. Atualmente, o estado da Bahia possui várias casas de candomblé que reclamam descendência direta de Ketu - povo que teria aportado no Brasil escravizado (Bay, 2013). Efon (pronuncia-se Éfan) é uma nação do candomblé oriunda das terras de Ekiti-Efon, porém, no Brasil é utilizado o termo Lokiti Efon. É uma grande nação que na África ainda perdura, cultuando-se lá muitos orixás que se perderam no caminho para o nosso país. Relata-se que a nação de Efon tenha perdido um pouco de sua abrangência para a nação Ketu em nosso território no decorrer do tempo, mas seus adeptos continuam preservando suas raízes e tradições (Evangelista, 2013), possivelmente devido a um processo chamado nagoização/nagocracia (Botão, 2007).

A cidade de Uberaba (MG) conta com terreiros de Candomblé distribuídos entre todas as nações. Os terreiros das nações pesquisadas mostraram em comum o fato de possuírem matrizes africanas; realizarem cerimônias públicas e privadas, essas restritas apenas aos adeptos do Candomblé, iniciados no culto ou não; serem animistas e terem convivência com as forças da natureza e ancestrais. Do ponto de vista estrutural e físico, os terreiros visitados são muito diferentes entre si, fato que pode ser explicado por se tratar de nações diferentes, tanto no número de integrantes, quanto em ornamentação para louvar os sagrados. Apesar dos dois lugares terem seus nomes pintados na parede principal dos salões, somente o terreiro da nação Efon era nitidamente indicado como templo religioso quando avistado na rua.

No período de coleta de dados e nos dias das cerimônias públicas que foram assistidas, as nações apresentaram cerca de 20 (Efon) e 80 (Ketu) participantes. Seguindo essa mesma ordem, o terreiro de Efon visitado conta com algumas estátuas no alto de uma parede ao fundo, é parcialmente coberto por conta da área com plantas e tem o teto coberto por bandeirinhas brancas. No terreiro de Ketu, nenhuma imagem foi encontrada no espaço onde o público circula; se há alguma, fica dentro dos cômodos onde apenas alguns Omo Orisa (filhos de Orixá - designação de qualquer pessoa iniciada no Candomblé Ketu) têm acesso. Nesse, o salão só é adornado quando há festividades, as bandeirinhas são azuis e brancas e em uma parede é possível notar fotos de todas as Ajoye/Yaroba (zeladoras dos orixás que não entram em transe) da casa, do Babalorixá (popularmente chamado de Pai de Santo) e da avó de Santo. A presença dessas fotos evidencia o espaço concedido à tradição e o respeito a essa hierarquia e a essa linhagem.

As giras referem-se aos toques públicos e voltados para atendimento à população, por meio de passes e consultas. Geralmente, o local é iniciado pela acolhida e esta é realizada por pessoas de cargo dentro do Terreiro, sendo que depois inicia-se, com o toque dos atabaques, o chamamento das entidades e estas realizam as consultas aos presentes. Vale destacar que no Candomblé são cultuados os sagrados em suas mais diversas formas e manifestações. No entanto, foi possível identificar a presença de entidades da Umbanda nos Terreiros observados, como caboclos e boiadeiros. 
No candomblé, existem basicamente três tipos de indivíduos: pessoas que incorporam (ou seja, manifestam fisicamente sua/suas divindade/divindades), as Ajoyes/Yaroba (nomenclatura utilizada no Candomblé Ketu) - mulheres que não incorporam (e, geralmente, são encarregadas de cuidar das divindades espirituais), os Ogans - homens que não incorporam (e, geralmente, ficam encarregados da percussão, de entoar os cânticos sagrados do ambiente e segurança do local do terreiro). Ajoyes e Ogans não podem se tornar pais ou mães de santo mesmo que tenham completado os necessários sete anos de feitura no santo, sendo que no Candomblé acredita-se que estes, ogans ou ajoyes, já nascem feitos, necessitando "apenas" da confirmação e, posteriormente, as demais obrigações (confirmação, um, três, sete, 14 e 21 anos). As pessoas que incorporam, vulgarmente chamadas de "Virantes" (no sentido de "virar no orixá") são subdivididas em: Abian (pessoa não iniciada nos segredos da religião), Iyawo (iniciados que possuem até sete anos), Egbomis (iniciados e que já tomaram a obrigação de sete anos).

Foram mencionados pelos participantes os seguintes orixás como representantes principais de seus orís (cabeça, mente): Oxóssi, Iansã, Ogum, Oxum, Ossaim, Oxumarê,, Iemanjá, Oxaguian (Oxalá em sua forma mais jovem e guerreira), Omulu (ou Obaluaiê), Logun-Edé, Xangô. Essas informações são importantes dentro do contexto da pesquisa, por estarem diretamente associadas a elementos bioecológicos como, por exemplo, a dimensão "Pessoa", relacionada às características pessoais dos participantes. No Candomblé, as características dos orixás, por extensão, podem ser visualizadas em seus adeptos. Assim, adeptos que são interpretados como "filhos" de um determinado orixá tendem a expressar comportamentos e modos de ser alinhados a essa entidade (Goldman, 2012). Por essa razão, essas características, assim como as relacionadas a cada nação dos terreiros dos quais os voluntários fazem parte, além dos cargos por eles ocupados nesses locais, são importantes em uma análise bioecológica. Pelas atribuições que assumem dentro de suas comunidades religiosas, por exemplo, os participantes podem ser categorizados da seguinte maneira: um Pai de Santo, duas Mães de Santo, três Ogans, três Ekedis, oito Egbomis. Os dados sociodemográficos são apresentados na Tabela 1. 
Tabela 1. Caracterização dos participantes, nomenclaturas de Cargo/Posto/Função transcritas como relatado durante a coleta de dados.

\begin{tabular}{|c|c|c|c|c|c|c|}
\hline & $\begin{array}{c}\text { Cargo / Posto / } \\
\text { Função }\end{array}$ & Idade & $\begin{array}{l}\text { Idade } \\
\text { de santo }\end{array}$ & $\begin{array}{l}\text { Estado } \\
\text { civil }\end{array}$ & Escolaridade & Profissão \\
\hline \multirow{9}{*}{$\begin{array}{l}\mathrm{K} \\
\mathrm{E} \\
\mathrm{T} \\
\mathrm{U}\end{array}$} & Babalorixá & 40 & 24 & Solteiro & $\begin{array}{c}\text { Pós- } \\
\text { Graduação }\end{array}$ & Advogado \\
\hline & IyaKekerê & 36 & 12 & Casado & $\begin{array}{l}\text { Médio } \\
\text { Completo }\end{array}$ & Secretária \\
\hline & Apá Osí & 38 & 7 & Casada & $\begin{array}{l}\text { Fundamental } \\
\text { Completo }\end{array}$ & Vidraceiro \\
\hline & IyaMayê & 50 & 7 & Casada & $\begin{array}{l}\text { Superior } \\
\text { Completo }\end{array}$ & Secretária \\
\hline & Balógun & 62 & 9 & Casado & $\begin{array}{l}\text { Básico } \\
\text { Completo }\end{array}$ & Aposentado \\
\hline & Olopondá & 41 & 7 & Casada & $\begin{array}{l}\text { Fundamental } \\
\text { Incompleto }\end{array}$ & Pensionista \\
\hline & Ekedi & 31 & 8 & Solteira & $\begin{array}{l}\text { Médio } \\
\text { Completo }\end{array}$ & Cabeleireira \\
\hline & Babalossayn & 47 & 17 & Solteiro & $\begin{array}{l}\text { Fundamental } \\
\text { Completo }\end{array}$ & Metalúrgico \\
\hline & Iyalaxé & 62 & 10 & Solteira & $\begin{array}{l}\text { Fundamental } \\
\text { Completo }\end{array}$ & Costureira \\
\hline \multirow{5}{*}{$\begin{array}{l}\mathrm{E} \\
\mathrm{F} \\
\mathrm{O} \\
\mathrm{N}\end{array}$} & Iyalorixá & 54 & 23 & Casada & $\begin{array}{c}3 \text { Superior } \\
\text { Completos, } \\
2 \text { Especializa- } \\
\text { ções e } 1 M B A\end{array}$ & Enfermeira \\
\hline & Ekedi & 26 & 14 & Solteira & $\begin{array}{l}\text { Superior } \\
\text { Completo }\end{array}$ & $\begin{array}{c}\text { Assistente } \\
\text { Social }\end{array}$ \\
\hline & Dofonitinho & 21 & 13 & Solteiro & $\begin{array}{l}\text { Superior } \\
\text { Incompleto }\end{array}$ & Estudante \\
\hline & Dofono & 29 & 7 & Solteiro & $\begin{array}{l}\text { Superior } \\
\text { Completo }\end{array}$ & $\begin{array}{l}\text { Educador } \\
\text { Infantil }\end{array}$ \\
\hline & Dofono & 22 & 14 & Solteiro & $\begin{array}{l}\text { Superior } \\
\text { Incompleto }\end{array}$ & Cabeleireiro \\
\hline
\end{tabular}

O nome pelo qual cada adepto é conhecido em seus terreiros representa uma função ou hierarquia. Na nação Efon os nomes Dofono e Dofonitinho, por exemplo, representam a ordem dessas pessoas dentro de seus "barcos" quando decidiram nascer para a vida espiritual. Geralmente, pelo desprendimento de recursos materiais e humanos, que requer ajudar a preparar alguém para se tornar Iyawo, muitos Abians se organizam entre si para realizarem a iniciação juntos. Esse aglomerado de pessoas, quando iniciado o processo de iniciação no Candomblé, é chamado de "Barco" [de Iniciação] e no momento em que se iniciam os procedimentos litúrgicos relativos ao culto, os abians passam a ser chamados de Yawo (Carneiro, 2008). 
De acordo com a bibliografia acerca do candomblé, no terreiro de Ketu, certos cargos, por suas atribuições, são outorgados somente a filhos de orixás relacionados à função, como são os casos do Babalossaym (filho de Ossaim), Oju Oba (filho de Xangô) e do Balogun (filho de Ogum). Em síntese, os cargos que surgiram durante a pesquisa e pertencentes a essa nação, de acordo com Carneiro (2008), são comuns também à nação Nagô e representam: o Babalorixá é o posto mais elevado do Ilê (casa de candomblé); a Iya Kekere (ou Mãe Pequena em português) substitui o Babalorixá ou Iyalorixá eventualmente; o Opá Òtún literalmente o braço esquerdo do zelador, e Opá Osi, o braço esquerdo. A Iya Mayê atua com as coisas mais secretas do axé - e, especificamente, nesse terreiro também é a Ajoye principal. O Balogun é como se fosse um general do local, devendo zelar pela segurança e organização - esse título militar yorubano só pode ser concedido a um filho de Ogum (orixá da guerra) e, nesse caso, foi destinado a um Ogan de Ogum. A Olopondá possui grande responsabilidade na iniciação e no âmbito altamente secreto ligado à orixá Oxum. O Babalossayn é o responsável pela colheita das folhas, é um cargo de extrema importância, pois no Candomblé nenhum ritual é feito sem folhas, destinadas aos filhos de Ossaim, pois esse é o orixá das ervas medicinais e litúrgicas. Por fim, a Iyalaxé é a mãe que distribui o axé (energia, força) nos rituais, sendo igualmente imprescindível.

Os participantes mais novos entrevistados estavam presentes na casa de Efon, assim como os que apresentaram maior escolaridade. A maior parte dos integrantes casados esteve presente no terreiro de Ketu. Os dois dirigentes das casas se destacam na cidade de Uberaba tanto como profissionais quanto como zeladores de santo, e conseguem promover a cultura africana sempre que podem e são reconhecidos e convidados para eventos.

\section{Análise bioecológica das trajetórias desenvolvimentais: o papel da tradição e da socialização}

Os terreiros visitados e estudados atuam como "microssistemas", possuindo suas próprias regras e maneiras de funcionar. Essas regras são construídas tanto a partir de tradições transmitidas por seus terreiros de origem quanto pelo modo de trabalhar de cada dirigente, bem como pelas características da comunidade, dos atendimentos prestados e da própria releitura que se opera a partir das tradições de matriz africana. O "mesossistema" é constituído pelos outros terreiros de matriz africana da região com os quais estabelecem relações. Em geral, os participantes relataram que são poucas e cordiais as visitas às outras casas, ocorrendo por ocasião de festividades e quando há relações de forte amizade entre os adeptos e dirigentes dessas comunidades. Sobre a ocorrência ou não dessas visitas entre terreiros, um dos adeptos foi mais explícito e esclareceu porque há parcimônia nesses relacionamentos:

É raro eu ir, mas eu vou de vez em quando é na umbanda aonde eu ia. Às vezes vou para fazer uma visita, agradeço muito pelo que me deu. Ele [o Babalorixá] não gosta que fica andando em outras casas porque você não sabe como vai estar as outras casas, não sabe como que eles vão te receber. Às vezes você pode entrar lá de uma forma e sair pior do que você entrou. Então, por isso a gente tem que evitar. (M. C., homem) 
A partir desse posicionamento, pode-se compreender que o receio existente se refere às possíveis influências desse mesossistema no desenvolvimento do adepto. Ao estar nesse novo ambiente, as relações proximais ali existentes tornam-se mais potentes, podendo repercutir no desenvolvimento da pessoa. Na perspectiva do Candomblé, essa interferência dá-se não apenas no nível energético e espiritual, mas também na hierarquia e nas relações de poder estabelecidas entre os terreiros. Assim, quando os adeptos visitam outros terreiros, abre-se a possibilidade de maior vulnerabilidade. Essa vulnerabilidade energética/espiritual reverberaria no desenvolvimento no adepto e também na comunidade de referência, pondo em relevo a inter-relação contínua entre o desenvolvimento do contexto (no caso, o terreiro) e da pessoa (o adepto).

Sobre o "exossistema", foi constatado que todos os dois terreiros possuem um terreiro de referência, mais antigo e localizado em cidades diferentes. Esses terreiros de referência, considerados sob a ótica do Candomblé como raiz, determinam indiretamente as regras e valores a serem seguidos e se cravam no conceito de tradição trabalhado no presente estudo. A transmissão dessa tradição, portanto, dar-se-ia a partir da interação entre essas diferentes casas, sendo que as mais antigas tendem a influenciar o modo como os terreiros mais jovens irão funcionar. Ao registrarem essa influência, demarcariam o poder da tradição na costura desses espaços e, consequentemente, no modo como as sociabilidades poderão ocorrer. O terreiro de referência da comunidade Ketu do presente estudo localiza-se em Salvador (BA), e o de Efon, em Santos (SP).

A importância dessas "matrizes" reside no fato do Candomblé ser composto de tradições nas quais nada é escrito e toda a sabedoria é transmitida oralmente (Carneiro, 2008; Prandi, 1990). Esses terreiros-matrizes (raiz) também podem funcionar como um macrossistema, uma vez que são os depositários das regras e dos preceitos que deram origem a diversas ramificações, ou seja, dos terreiros que foram se desenvolvendo em outras cidades a partir de uma ancestralidade comum. Esses macrossistemas detêm conhecimentos ancestrais e elementos históricos, sociais e culturais que compõem o repertório de significações e práticas de todos os terreiros que derivam dessas matrizes, compondo uma cadeia de significações centralizadas no poder da tradição.

No quesito das relações proximais, o que também emerge quando se discute a sociabilidade, foi constatado, neste estudo, como alguns dos participantes foram inseridos efetivamente na religião a partir do "convite" de alguma entidade/divindade/Orixá. Essas entidades, em momentos propícios da história de vida da pessoa, proporcionaram orientações espirituais, sobretudo a partir das incorporações e de oráculos, como o jogo de búzios, e indicaram que esse poderia ser um caminho a ser seguido, promovendo uma espécie de "chamamento". Para Goldman (2012), a questão do "dom" ou do que é "inato", marcado no destino da pessoa, é um elemento que demarca profundamente as religiões de matriz africana, o que também foi trazido pelos entrevistados como algo que estava em suas missões, em um processo com pouca ou nenhuma possibilidade de remanejamento. Essa missão, ou esse destino, atravessa não apenas a decisão por realizar a feitura do santo, como também emprega essa narrativa como forma de tecer as relações ecológicas e os percursos desenvolvimentais desses sujeitos em suas comunidades de referência.

Na dimensão "Pessoa”, observou-se que criações mais rígidas (indivíduos que cresceram em ambientes pouco permissivos) geraram lembranças mais fortes quando questionados sobre a infância - talvez pela carga emocional atrelada. Os adeptos que referiram uma criação mais flexível tiveram maior dificuldade para relatar um fato marcante da infância 
e um da adolescência. Seguindo o modelo bioecológico de Bronfenbrenner (2011), nessa dimensão ressaltam-se ainda três tipos de características da pessoa que moldam o curso de seu desenvolvimento humano: "disposições", "recursos bioecológicos" e "demandas". Todas elas puderam ser vislumbradas ao se estudar um princípio fundamental encontrado nessa religião: a paciência.

Converso muito com meus irmãos que estão começando agora e falo: "Olha, gente, não está na hora de vocês aprenderem, vocês estão querendo passar a carruagem na frente dos bois - como os antigos falavam". Acho que tudo dentro de uma casa de candomblé tem as horas e os momentos certos, porque quando eu comecei, eu ficava ansioso para chegar a hora de eu aprender. Tudo tem a hora. [...] Às vezes eles me perguntam e eu respondo: "Isso não posso te responder agora porque não é o momento certo, ainda não é o momento de te ensinar, mas ainda haverá o momento certo para sentar e te ensinar". Eu já passei por isso e explico para eles. (R. S., homem, grifo nosso)

Filho Pequeno é uma expressão que designa os médiuns mais novos, que possuem padrinhos ou madrinhas. Na realidade, todos os iniciados, além de seus Pais ou Mães de Santo, recebem um Pai ou Mãe Pequena - a quem devem recorrer para buscar orientações na ausência dos primeiros.

Nos "processos proximais" entendidos como o estabelecimento de atividades mediúnicas regulares, todos tiveram contato com umbanda ou candomblé ainda crianças ou adolescentes. Já adultos, alguns se afastaram por poucos anos dessas religiões, não deixando, contudo, de aplicar seus ensinamentos no dia a dia, somente transitando do papel de integrantes para o papel de assistentes. Apenas um dos entrevistados relatou que o núcleo familiar não aceitava completamente sua religião, embora respeitasse sua escolha. Todos mencionaram mais de uma religião presente em suas famílias, seja por algum irmão que preferiu não participar das crenças e princípios religiosos sob os quais cresceu, ou mesmo tios, que entraram em contato com outras práticas e que trocam experiências em reuniões familiares. Um adepto da nação Ketu contou que se iniciou na nação Bantu/ Angola (nação identificada na cidade, assim como a nação Jeje, porém, quando convidados, nenhum adepto, entre os contatados, pertencentes a estas nações apresentou interesse em participar) e anos depois fez a transição, tendo que cumprir novamente os preceitos e dar seguimento ao processo.

Vínculos familiares - mãe-filhos, marido-mulher, irmãos - puderam ser observados. As duas Iyalorixás possuem filhos adotivos e consanguíneos, além de zelarem por seus filhos de santo. Usualmente, pais e mães não se tornam pais e mães de santo de seus filhos, e outras pessoas igualmente capacitadas são convidadas para presidirem os rituais de iniciação. Não é uma obrigatoriedade, mas em terreiros de matriz africana, nem a mescla de vínculos como avós-netos e tios-sobrinhos é permitida quando se vai "colocar a mão" na cabeça de alguém. O que é realmente inaceitável é que o mesmo Babalorixá ou Iyalorixá comande o ritual de iniciação de marido e mulher, pois isso os tornaria irmãos de santo. O sacerdote pode ser o mesmo, mas em determinados acontecimentos secretos outra pessoa de confiança tem que interceder. Ambos os cônjuges podem pertencer à mesma casa de axé e até mesmo decidirem se iniciar no mesmo período, contudo, cada um deverá dormir em cômodo diferente durante todo o processo. 
Assim, pode-se destacar que existem dois contextos desenvolvimentais que são denominados de famílias: a família de origem, aqui podendo ser compreendida como a de laços de consanguinidade ou por adoção, e a família de santo, estabelecida a partir de rituais e da socialização no Candomblé. O que se pondera, a partir dos relatos, é que ambas as famílias atravessam o desenvolvimento dos participantes, sendo a família de santo mais evocada, até mesmo pelo fato de se tratar de uma investigação ocorrida em contexto religioso/ espiritual. A partir da noção de tradição, observa-se que os participantes assinalam a forte vinculação a uma hierarquia corporificada no candomblé. Assim, quando tratamos das relações nas famílias de santo, é importante assinalar como a tradição costura a socialização, mas também permite determinados posicionamentos (cargos) que acabam atravessando o desenvolvimento de seus adeptos.

Nesse ponto, também é conveniente evidenciar como as relações hierárquicas e interpessoais se dão na literatura do candomblé. Acredita-se que Ekedis e Ogans já nasceram "feitos" para seguirem esses caminhos espirituais, e são chamados de mães Ekedis e pais Ogans dentro dos terreiros. Eles são os olhos e ouvidos da casa, assim como cuidam dos médiuns que entram em transe. Assim, mães e pais do mundo material podem tornar-se filhos de seus filhos - que sejam Ajoyes ou Ogans - quando estão sob seus cuidados. Entre as relações fraternais estabelecidas dentro dos terreiros, não foram narrados desentendimentos. Reconhece-se que, por divergência de opiniões e de personalidades, conflitos cotidianos acontecem eventualmente. Mas como essas comunidades prezam, sobretudo, pelo respeito, logo são abordados os motivos desses desentendimentos. Os zeladores das casas de axé, mais do que cuidar da parte espiritual, exercem também a função de manter a ordem e harmonia entre os filhos e consigo. Mais do que exercer um cuidado regular das atividades mediúnicas dos filhos de santo, preocupam-se com os outros setores de suas vidas. O terreiro como sinônimo de casa e as relações interpessoais que lá se concentram como sinônimos de família atravessam a totalidade dos relatos. A "paternagem/maternagem" dos líderes espirituais pode ser observada no modo como essas figuras cuidam, acolhem, aconselham e orientam seus filhos de santo para além dos aspectos religiosos/espirituais. Assim, não se observam cisões entre o religioso e o não religioso nas narrativas desses adeptos, mas uma integração/integralidade que é condizente com os pressupostos do próprio candomblé. Narrativas semelhantes foram trazidas nos estudos de Goldman (2012) e Rabelo (2014).

$\mathrm{Na}$ dimensão do "Macrotempo" apareceram relatos entremeados por densa carga emocional quando se dão conta de que seguir uma religião de matriz africana foi passado de geração para geração. Os que haviam experimentado isso no passado demonstraram gratidão por suas raízes e afirmaram terem aprendido valores morais desde cedo por conta dos ensinamentos da religião. A palavra respeito, por exemplo, foi amplamente proferida pelos participantes ao se referirem às entidades e tudo o que elas representam em suas vidas. Os processos desenvolvimentais dos médiuns dessas comunidades de matriz africana foram permeados de fé desde quando eram muitos jovens. Assim, reafirma-se o poder do papel da tradição no desenvolvimento dessas pessoas.

Transformações identitárias, como assumir um novo papel diante da sociedade e dos familiares, foram sentidas pelos participantes quando passaram pelo processo de iniciação e mais fortemente quando completaram os sete anos desse ritual, momento considerado de maior maturidade na religião. Alcançar esse marco significa que essas pessoas tornaram-se modelos dentro de suas comunidades e contraíram a responsabilidade de ensinar os mais novos, levando adiante o legado da tradição. Pode-se depreender que a transmissão 
da tradição é potencializada quando a pessoa passa pela feitura dos sete anos: a essas pessoas, dá-se a autorização para que as mesmas possam transmitir e também zelar pela tradição. Essas transições ecológicas operadas pelos processos de iniciação, de "feitura do santo" (Camargo et al., 2018) mostraram-se de extrema importância nos percursos desenvolvimentais desses adeptos.

Os processos de desenvolvimento espiritual pelos quais essas pessoas passam até se tornarem iniciados incluem diversas restrições periódicas e/ou específicas. São restrições como: não ingerir mais certos alimentos, vestir roupas brancas por um determinado período e em dias específicos, abdicar de toda e qualquer vaidade dentro dos cômodos religiosos, deixar de frequentar certos locais por um tempo, recolher-se mais cedo, ser acordado para rezar, tomar banhos frios de ervas, comer com as mãos algumas vezes e sentar-se em altura inferior aos mais velhos de santo. Esses princípios de comedimento e moderação são transmitidos como regras entre os membros do terreiro, representando tanto uma submissão aos preceitos religiosos como um respeito à ancestralidade que atravessa a constituição de costumes, tradições, sociabilidades e modos de ser nessas comunidades. Essas tradições e ancestralidades inserem-se no macrossistema e também podem ser vislumbradas nas relações proximais, no modo de ser de cada um, nas vestimentas, nos rituais, na maneira de vivenciar os preceitos, no microssistema.

Nos terreiros, os participantes adquirem uma segunda família e, por vezes, estabelecem relações mais fortes com seus vinculares de santo do que com seus consanguíneos, tamanha a percepção do apoio recebido a partir dessa rede, o que também foi sugerido no estudo de Rabelo (2014). Social e culturalmente, quando completam os sete anos de feitura, sentem-se mais seguros da diferença que podem orquestrar em suas regiões, divulgando a religião e ajudando a dirimir os preconceitos que elas enfrentam. A religião não é sentida como um peso por esses adeptos, como é comum a lógica cristã-ocidental, embora quanto maior for o tempo de santo (tempo de iniciação), maior a responsabilidade que adquirem dentro de suas comunidades religiosas. Seus ensinamentos são sentidos e estão presentes até nos detalhes mais sutis do dia a dia, seja na forma como saúdam as pessoas, agradecem a mais um dia ou pedem permissão aos seres superiores para pisar em certos ambientes. A hierarquização existente é percebida como de suma importância, devendo ser respeitada em qualquer momento, independentemente de quantos anos de santo (de feitura) se tenha.

A partir da análise desses marcadores, em uma perspectiva bioecológica, deve-se compreender que o desenvolvimento desses adeptos é atravessado por elementos que dialogam tanto com o mundo material (contextos físicos, espaços, tempos) quanto com o mundo psíquico, de caráter interno, que pode ser interpretado a partir da religiosidade e da espiritualidade. Assim, esse modelo revela-se potente por permitir o interjogo entre esses elementos que constituem o desenvolvimento humano. O candomblé é um contexto desenvolvimental que possui uma concretude em seus adeptos. Os contextos ecológicos podem e devem se abrir para a consideração de tradições e sociabilidades que recuperam hierarquias próprias e legítimas de determinados cenários, possibilitando leituras e interpretações para famílias que não se sustentam em vínculos de consanguinidade ou por adoção, mas por ancestralidades não materiais. 


\section{Considerações finais}

Este estudo evidenciou como as noções de tradição e sociabilidade atravessam os processos desenvolvimentais dos adeptos do candomblé, permitindo a construção de normas, relações e itinerários que encontram nas comunidades de referência um espaço de acolhimento e pertencimento. Ao se sentirem acolhidas, respeitadas e pertencentes, essas pessoas podem se desenvolver e partilhar em comunidade os ganhos desses processos, o que envolve o aprendizado e a transmissão daquilo que vai se conhecendo. A ancestralidade que atravessa as religiões de matriz africana não sugere a transmissão como única forma de perpetuação, mas permite que novos arranjos deem contornos diversos à religião, o que fica evidenciado na diversidade observada em campo.

Obviamente que se trata de uma visão ainda descritiva e que deve potencializar outras investigações que permitam ampliar as inteligibilidades ora apresentadas. Os entrevistados, pelo tempo de iniciação, assumem a responsabilidade de transmitir os conhecimentos religiosos, preservando a tradição. Desse modo, aventa-se que os elementos da tradição puderam ser apreendidos de modo mais evidente no presente estudo por se tratarem de iniciados com maior tempo de experiência e maior engajamento nesse cenário religioso.

O poder dessa transmissão deve ser compreendido a partir dos itinerários desses adeptos. Esses itinerários não se mostram cristalizados e determinados, mas, em uma inteligibilidade bioecológica, circunscritos. Assim, os processos desenvolvimentais comportariam mudanças nesses itinerários, ainda que esses movimentos se deem orientados por modelos, regras de conduta e prescrições para além do mundo material, compondo uma tradição anfíbia justamente por considerar elementos religiosos e espirituais. O cotidiano dos terreiros de Uberaba (MG), pelos dados aqui discutidos, parece reafirmar cadeias tradicionais também observadas em outros centros, como os de Salvador (BA) e do Rio de Janeiro (RJ), sendo lícito considerar que as particularidades de cada terreiro e de cada nação tornam-se elementos de menor importância quando consideramos o poder da tradição e da sua transmissão no Candomblé, o que nos remete à dimensão do macrossistema e a sua expressão nos micros, mesos e exossistemas. Em estudos vindouros, recomenda-se o endereçamento de discussões que possam costurar as tradições (macro e microssociais) e as sociabilidades como fatores de proteção à intolerância religiosa, reafirmando a ancestral resistência dessas comunidades e sua complexa relação com fenômenos em escrita permanente como o desenvolvimento, o candomblé e o próprio sujeito. 


\section{Referências}

Araújo, P. C. (2018). Segredos do Poder: hierarquia e autoridade no Candomblé. São Paulo: Arché. Bastide, R. (2009). O candomblé da Bahia. Rio de Janeiro: Companhia das Letras.

Bay, E. G. (2013). Ketu lembrado: a persistência da cultura e da história ioruba no mundo atlântico. Afro-Ásia, 47, 407-410. 10.1590/S0002-05912013000100011

Botão, R. U. S. (2007). Para além da nagocracia: a (re)africanização do candomblé nação angola-congo em São Paulo. Dissertação de Mestrado, Programa de Pós-graduação em Ciências Sociais, Faculdade de Filosofia, Ciências e Letras, Universidade Estadual Paulista, Marília, São Paulo.

Brant Carvalho, J. B., \& Bairrão, J. F. M. H. (2017). Fios da razão: Tradição e pluralidade da Umbanda em Pontal. Interação em Psicologia, 21(2), 147-156.

Bronfenbrenner, U. (2011). Bioecologia do desenvolvimento humano: tornando os seres humanos mais humanos. Porto Alegre: Artmed.

Camargo, A. F. G., Scorsolini-Comin, F., \& Santos, M. A. (2018). A feitura do santo: percursos desenvolvimentais de médiuns em iniciação no Candomblé. Psicologia ङ゚ Sociedade, 30, e 189741. https://doi.org/10.1590/1807-0310/2018v30189741

Carneiro, E. (2008). Candomblés da Bahia. São Paulo: Martins Fontes.

Castillo, L. E. (2017). O terreiro de Gantois: redes sociais e etnografia histórica no século XIX. Revista de História, 176, 1-57. a05616.

Cerqueira, A. (2007). Uma reflexão sobre o surgimento do Candomblé. Histórica (São Paulo), $21,2-16$.

Evangelista, D. (2013). Emoção não é coisa de Equede: mudança de status e relações de poder no Candomblé. Revista Intratextos, 4(1), 93-106. 10.12957/intratextos.2013.6250

Goldman, M. (2005). Formas do saber e modos do ser: multiplicidade e ontologia no candomblé. Religião e Sociedade, 25(2), 102-120.

Goldman, M. (2012). O dom e a iniciação revisitados: o dado e o feito em religiões de matriz africana no brasil. Mana, 18(2), 269-288. 10.1590/S0104-93132012000200002

Hobsbawm, E. (1984). "Introdução". In E. Hobsbawn \& T. Ranger, A invenção das tradições (pp. 9-23). Rio de Janeiro: Paz e Terra.

Jabert, A. \& Facchinetti, C. (2011). A experiência da loucura segundo o espiritismo: uma análise dos prontuários médicos do Sanatório Espírita de Uberaba. Revista Latinoamericana de Psicopatologia Fundamental, 14(3), 513-529. 10.1590/S1415-47142011000300008

Lewgoy, B. (2001). Chico Xavier e a cultura brasileira. Revista Antropologia, 44(1), 53-116. 10.1590/S0034-77012001000100003

Macedo, A. C. \& Bairrão, J. F. M. H. (2011). Estrela que vem do Norte: os baianos na umbanda de São Paulo. Paidéia (Ribeirão Preto), 21(49), 207-2 16. 10.1590/So103-863X2011000200008

Martins, E. \& Szymanski, H. (2004). A abordagem ecológica de Urie Bronfenbrenner em estudos com famílias. Estudos e Pesquisas em Psicologia, 4(1), 63-77.

Moreira-Almeida, A. (2013). Pesquisa em mediunidade e relação mente-cérebro: revisão das evidências. Revista de Psiquiatria Clínica, 4O(6), 233-240. 10.1590/So 101-60832013000600005 
Pierucci, A. F. (2004). "Bye bye, Brasil”: O declínio das religiões tradicionais no Censo 2000. Estudos Avançados, 18(52), 17-28. 10.1590/S0 103-40142004000300003

Poletto, M. \& Koller, S. H. (2008). Contextos ecológicos: promotores de resiliência, fatores de risco e de proteção. Estudos de Psicologia (Campinas), 25(3), 405-4116. 10.1590/So 103166X2008000300009

Prandi, R. (1990). Modernidade com feitiçaria: candomblé e umbanda no Brasil do século XX. Tempo Social, 2(1), 49-74. 10.1590/ts.v2i1.84787

Rabelo, M. C. M. (2014). Enredos, feituras e modos de cuidado: dimensões da vida e da convivência no candomblé. Salvador: EDUFBA.

Santos, E. F., \& Alves, J. (2017). A tradição oral para povos africanos e afrobrasileiros: relevância da palavra. Revista da ABPN, 9 (n.spe.), 50-76.

Santos, J. T. \& Santos, L. C. C. (2013). "Pai de santo doutor": escolaridade, gênero e cor nos terreiros baianos. Afro-Ásia, 48, 213-236. 10.1590/S0002-05912013000200006

Scorsolini-Comin, F. (2017). Espiritualidade e brasilidade na clínica etnopsicológica. Psicologia Clínica, 29(2), 319-338.

Scorsolini-Comin, F. \& Campos, M. T. A. (2017). Narrativas desenvolvimentais de médiuns da umbanda à luz do modelo bioecológico. Estudos e Pesquisas em Psicologia, 17(1), 364-385.

Simões, A. S. M. \& Salaroli, T. P. (2017). O retrato da intolerância religiosa no Brasil e os meios de combatê-la. Revista Eletrônica de Teologia e Ciências da Religião, 5(2), 411-430.

Verger, P. (2002). Fluxo e refluxo do tráfico de escravos entre o Golfo do Benin e a Bahia de Todos os Santos (dos séculos XVII-XIX). Salvador: Corrupio.

\section{FABIO SCORSOLINI-COMIN \\ https://orcid.org/0000-0001-6281-3371}

Doutor em Psicologia pela Universidade de São Paulo e docente da Escola de Enfermagem de Ribeirão Preto da Universidade de São Paulo.

Endereço institucional: Departamento de Enfermagem Psiquiátrica e Ciências Humanas, Escola de Enfermagem de Ribeirão Preto da USP. Avenida Bandeirantes, 3900, Monte Alegre, Ribeirão Preto/SP. CEP: 14040-902 E-mail: fabio.scorsolini@usp.br

\section{ARIADNE CHRISTIE SILVA RIBEIRO \\ https://orcid.org/0000-0002-1939-4076}

Psicóloga pela Universidade Federal do Triângulo Mineiro.

E-mail: ariadne.christie@gmail.com

\section{RONAN DA SILVA PARREIRA GAIA \\ https://orcid.org/0000-0003-2342-0019}

Pedagogo e Mestrando pelo Programa de Pós-graduação em Enfermagem Psiquiátrica da Escola de Enfermagem de Ribeirão Preto da Universidade de São Paulo.

E-mail: ronangaia@yahoo.com.br 


\begin{tabular}{|c|c|}
\hline Histórico & $\begin{array}{l}\text { Submissão: 23/04/2019 } \\
\text { Revisão: 26/09/2019 } \\
\text { Aceite: } 30 / 10 / 2019\end{array}$ \\
\hline $\begin{array}{l}\text { Contribuição } \\
\text { dos autores }\end{array}$ & $\begin{array}{l}\text { Concepção: A.C.S.R.; F.S.C. } \\
\text { Coleta de dados: A.C.S.R. } \\
\text { Análise de dados: F.S.C.; R.S.P.G. } \\
\text { Elaboração do manuscrito: F.S.C.; R.S.P.G. } \\
\text { Crítico revisões de conteúdo intelectual importante: } \\
\text { F.S.C.;.S.P.G. } \\
\text { Aprovação final do manuscrito: F.S.C. }\end{array}$ \\
\hline $\begin{array}{l}\text { Consentimento } \\
\text { de uso de imagem }\end{array}$ & Não se aplica \\
\hline $\begin{array}{l}\text { Aprovação, ética } \\
\text { e consentimento }\end{array}$ & $\begin{array}{l}\text { A realização do presente estudo foi aprovada pelo Comitê } \\
\text { de Ética em Pesquisa da Escola de Enfermagem de Ribeirão } \\
\text { Preto da Universidade de São Paulo }\end{array}$ \\
\hline Financiamento & $\begin{array}{l}\text { CNPq (Bolsa de Produtividade em Pesquisa concedida ao } \\
\text { primeiro autor) }\end{array}$ \\
\hline
\end{tabular}

